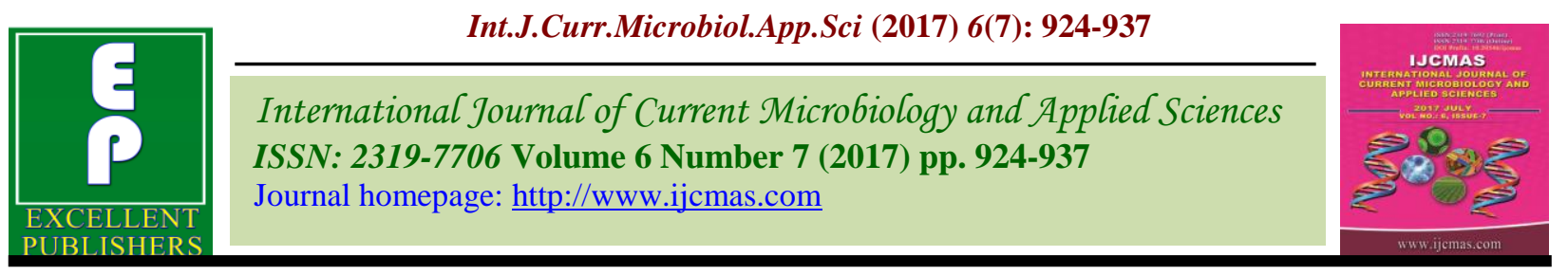

Original Research Article

https://doi.org/10.20546/ijcmas.2017.607.114

\title{
Changes in Quality of Broccoli Stored under Modified Atmosphere Packaging in Polymeric Films
}

\author{
Rakesh Kumar* and Gurdarshan Singh \\ Krishi Vigyan Kendra, Faridkot- 151203, Punjab, India \\ *Corresponding author
}

\begin{abstract}
A B S T R A C T
Keywords

Broccoli,

Modified

atmosphere

packaging,

Polymeric films,

Chlorophyll.

Article Info

Accepted:

14 June 2017

Available Online:

10 July 2017

The study was under taken to assess the impact of differential in-pack gaseous conditions generated through modified atmosphere packaging (MAP) using different packaging films (low density polyethylene (LDPE) and polypropylene (PP), having thickness 150 guage and bag area $0.14 \mathrm{~m}^{2}$ ) with and without perforations and variable head space (HS) on the quality of broccoli stored for 10 days at $15^{\circ} \mathrm{C}$ and relative humidity (RH) of $75 \%$. Quality of stored broccoli was adjudged on the basis of retention of chlorophyll for all the packaging treatments, for the storage period. Quality parameters viz., $\beta$ carotene and ascorbic acid that affect the chlorophyll retention were also recorded. The final retention levels of quality parameters were influenced by package gaseous condition. The Chlorophyll and $\beta$-carotene retention were recorded better in perforated LDPE film packages having $0.8 \mathrm{HS}$ than in PP film packages at the end of storage period. Similar results were recorded for ascorbic acid i.e. higher values in perforated LDPE packages having $0.8 \mathrm{HS}$. The low in-pack $\mathrm{O}_{2}$ concentration (approximately 4-5\%) along with high $\mathrm{CO}_{2}$ concentration (approximately 9-11\%) may have enhanced the retention of antioxidant components i.e. $\beta$-carotene and ascorbic acid for longer period, which in turn have resulted in increase in chlorophyll retention. The results indicated that packaging film permeability for $\mathrm{O}_{2}$ and $\mathrm{CO}_{2}$ or head space might be such that equilibrated $\mathrm{O}_{2}$ concentration remains near to $4-5 \%$ and $\mathrm{CO}_{2}$ concentration to $9-11 \%$, so as to affect a beneficial retention of chlorophyll with lesser browning.
\end{abstract}

\section{Introduction}

\section{Practical applications}

Broccoli is a high value crop and is an important source of vitamins and anticarcinogenic substances (Nestle, 1998). Broccoli is a high respiring crop, which results in reduction of shelf- life and quality in a short time. Traditional methods of packaging and handling reduce the shelf-life and various nutritional and phyto-chemical components of fresh produce. Temperature control and atmospheric modifications help to maintain the produce quality as they reduce the respiration rate and thus enhance the shelf-life of produce. The present study was taken up to know respiratory behavior of fresh broccoli at $15^{\circ} \mathrm{C}$ temperature and $75 \%$ relative humidity (commonly maintained during transportation and retail distribution in India) and also to see the effect of different polymeric films and packing conditions on its quality parameters. The results showed that the use of polymeric film packages can help in maintaining the sensory and nutritional 
quality of broccoli and hence shows the potential of MAP for packaging of broccoli. MAP can be beneficial method for safe storage, transportation and handling of this highly perishable produce in the food chain, as compared to traditional storage techniques.

Vegetables are the natural source of vitamins, minerals and other nutrients required for human development. However, they suffer losses in their quality and quantity between harvest and consumption. Since, fruits and vegetables are highly perishable, efficient post harvest treatment is an absolute necessity for effective extension of shelf life. Broccoli is a good source of vitamins A and C. It is also reported to have anti-cancerous properties and medicinal properties which can cure heart ailments and diabetes. The broccoli contains 89.1 percent moisture, $3.6 \mathrm{~g}$ protein, $0.3 \mathrm{~g}$ fat, $5.9 \mathrm{~g}$ carbohydrates, $2500 \mathrm{IU}$ vitamin A, 113mg vitamin C, $78 \mathrm{mg}$ phosphorus, $1.1 \mathrm{mg}$ iron, $0.23 \mathrm{mg}$ riboflavin, $0.9 \mathrm{mg}$ niacin and $0.1 \mathrm{mg}$ thiamin per $100 \mathrm{~g}$ (Dhaliwal, 2007).

Today's consumer prefers perishable produce in fresh form and their demand is growing day by day in daily food requirement. The fresh produce is sold in variety of commercial packages. Broccoli have high respiration rate and hence improper selection of temperature and packaging material shortens its shelf-life at the retailer's level. Broccoli also has shorter life at room temperature due to immaturity of texture at the moment of the harvest as well as due to various other physiological factors regulated by the genetic mechanisms (Vamos, 1981). Chemical treatments, temperature control and atmospheric modifications by packaging in polymeric films can maintain produce quality and enhance shelf-life of fruits and vegetables viz. decay, browning, discoloration of pigments, loss of flavor, texture and nutritional quality (Wiley, 1994; Brecht,
1995). The green broccoli is preferred by the buyer and fetch premium price. Chlorophyll is related with the bright green colour and if not properly cared after harvest it degrades during storage, transport and handling. The major changes taking place during its senescence include degradation of chlorophyll, opening of the flower buds, loss of turgidity, off-odors development, loss of nutritional value and an increase in the peroxidase activity (Hansen, 2001). Hence, it is necessary to avoid senescence of green coloured crops such as broccoli to retain its chlorophyll content and thus the commercial value.

Modified atmosphere packaging (MAP) of produce in polymeric films in combination with storage at low temperature extends the shelf-life of fresh produce, through interaction of the natural process of respiration of produce with the restricted gaseous exchange across the polymeric film package to control the in-pack $\mathrm{O}_{2}$ and $\mathrm{CO}_{2}$. The steady state inpack gaseous concentrations have been reported to delay the senescence, maintenance of physico-chemical constituents and extension of shelf-life of different crops (Pentima et al., 1995; Saito et al., 2000; Rai and Paul, 2007). Selection of an appropriate packaging film (perforated, non-perforated) for broccoli is an important criterion for its storage, as improper selection will lead to development of off-flavour and loss of quality in a very short period. The package fill weight (or in-pack head space) also affects the various physico-chemical constituents of the packaged produce through creation of different in-pack gaseous concentrations of $\mathrm{O}_{2}$ and $\mathrm{CO}_{2}$.

The present study was conducted to investigate the impact of polymeric films and variable in-pack head space on physicochemical constituents of broccoli stored at $15^{\circ} \mathrm{C}$ and relative humidity of $75 \%$ under modified atmospheres. 


\section{Materials and Methods}

The farm-fresh broccoli obtained from the farmer of village Bargari, district Faridkot was sorted for uniform head-size. The harvested broccoli heads were then air-cooled for $2 \mathrm{~h}$, inside a cold room (Frig India Ltd., New Delhi, India) maintained at $15^{\circ} \mathrm{C}$ and $75 \%$ relative humidity. Pre-cooling prepared the broccoli heads for subsequent storage temperature regime.

\section{Packaging and storage}

After pre-cooling, the broccoli heads were packed in packages $(27.5 \times 25.5 \mathrm{~cm}$; bag area $0.14 \mathrm{~m}^{2}$ ) made from two types of polymeric film (LDPE and PP). Different quantities of the produce were packed to vary the headspace volume. The perforated (2 perforation per package) and non-perforated packages were selected for the study. The diameter of each perforation was $0.3 \mathrm{~mm}$ (Schreiner et al., 2007; Rai et al., 2008). Macro perforations provide additional gaseous diffusion across the film packages (Techavises and Hikida, 2008) and therefore can be used to increase the gas permeability of ordinary polymeric films. The package used for packaging were procured from market of same gauge (150 gauge), but on actually measuring the thickness in laboratory with the help of thickness tester (Labthink, model CHY-C2, China) it was found that thickness of LDPE film was $40 \mu \mathrm{m}$ and that of PP film was $36 \mu \mathrm{m}$. The gas permeability coefficients of the LDPE packaging film for $\mathrm{O}_{2}$ and $\mathrm{CO}_{2}$ at $15^{\circ} \mathrm{C}$, measured by a gas permeability tester (Labthink, model BTY$\mathrm{B} 1 \mathrm{P}$, China) were observed to be $5.96 \times 10^{-5}$ and $2.52 \times 10^{-4} \mathrm{ml} \quad \mathrm{m} \quad \mathrm{m}^{-2} \mathrm{~h}^{-1} \mathrm{kPa}^{-1}$, respectively and for the PP packaging film, they were observed to be $1.49 \times 10^{-5}$ and $5.24 \times 10^{-5} \mathrm{ml} \mathrm{m} \mathrm{m}^{-2} \mathrm{~h}^{-1} \mathrm{kPa}^{-1}$, respectively. Effective permeability of gases and water vapour through perforations was estimated by the following relationship given by Techavises and Hikida (2008) which is valid for temperature range of $5-25^{\circ} \mathrm{C}$ and film thickness of less than $0.025 \mathrm{~mm}$. The effective permeability of the perforation was $0.986 \mathrm{ml} . \mathrm{h}^{-1} \mathrm{kPa}^{-1}$, taken to be equal for both $\mathrm{O}_{2}$ and $\mathrm{CO}_{2}$. Packaging was done inside the cold room itself, to minimize the respiration changes. The sample size was $250 \mathrm{~g}$ and $350 \mathrm{~g}$ resulting in head space (HS) of 0.8 and 0.7 respectively. The packages containing fresh broccoli heads were then heat sealed and kept for storage in an environmental control chamber (Vista Biocell Ltd., New Delhi, India). The gaseous concentration of $\mathrm{O}_{2}$ and $\mathrm{CO}_{2}$ in all the packages was assumed to be is $21.16 \%$ and $0.03 \%$ at the beginning of the storage. The control samples were kept unsealed under the similar environmental conditions. The experiments were replicated thrice. The observations were recorded after first, third, sixth and tenth day of storage. The weighing was done with help of an electronic weighing balance (having least count $0.001 \mathrm{~g}$ ). An average of four readings was taken for calculating the loss in weight (\%) of the material.

\section{Gas analysis of package headspace}

The headspace concentration of $\mathrm{O}_{2}$ and $\mathrm{CO}_{2}$ were analyzed using a portable headspace gas analyzer (Model 902 D Dualtrak, Quantek, USA). The instrument measured in-pack gas concentration using an electrochemical and infrared sensor (sensitivity: $0.1 \% \quad \mathrm{O}_{2}$ and $0.1 \% \mathrm{CO}_{2}$, accuracy $0.1 \% \mathrm{O}_{2}$ and $0.1 \% \mathrm{CO}_{2}$ ) for $\mathrm{O}_{2}$ and $\mathrm{CO}_{2}$ concentrations respectively. The instrument was calibrated before any experiment with standard gases. A particulate filter and a removable needle with dual sideport holes were used on the sampling probe to draw the headspace sample from the package with the help of an electronically controlled miniature pump. The drawn sample was fed simultaneously to the $\mathrm{O}_{2}$ and $\mathrm{CO}_{2}$ sensors and 
the concentration $\mathrm{O}_{2}$ and $\mathrm{CO}_{2}$ were directly read on the digital display panel of the instrument.

\section{Quantitative analysis of pigments}

The quantification of pigments (chlorophyll and $\beta$-carotene) was carried out as per Nagata and Yamashita (1992). One gram of broccoli sample was homogenized with $10 \mathrm{ml}$ of acetone and n-hexane (4:6) solution using a tissue homogenizer (Labco Ltd., India) for 30 $\mathrm{s}$ over ice. The homogenized solution was allowed to stand for $30 \mathrm{~s}$. One $\mathrm{ml}$ of the supernatant was taken and was diluted with 9 $\mathrm{ml}$ of the extract solution. The resulting solution was analyzed spectrophotometrically with the help of an UV-Vis spectrophotometer (Spectroscan 80DV, Biotech Engineering Management Company Limited, UK). Optical density of the solution was measured at wavelengths of 663,645 , 505 and $453 \mathrm{~nm}$. Acetone and n-hexane (4:6) solution was used as standard solution. The pigments were quantified and then expressed as $\mathrm{mg} / 100 \mathrm{~g}$ fresh weight (fw) of sample.

\section{Ascorbic acid determination}

The ascorbic acid concentration was estimated quantitatively as per the modified 2 , 6 dichlorophenolidophenol (DIP) method proposed by Klein and Perry (1982). One gram of broccoli sample was homogenized with $10 \mathrm{ml}$ of $1 \%$ metaphosphoric acid (v/v) over ice to avoid any chemical changes during extraction, using a tissue homogenizer for 1 min. The extract was centrifuged at $3000 \mathrm{rpm}$ in a cold centrifuge at $3^{\circ} \mathrm{C}$ for $15 \mathrm{~min}$. One $\mathrm{ml}$ of supernatant was mixed with $9 \mathrm{ml}$ of 0.05 mM DIP using a vortex shaker (Labco Ltd., India) for $15 \mathrm{~s}$ and optical density of the solution was measured against the blank at wavelength of $515 \mathrm{~nm}$. The standard curve for ascorbic acid was obtained within the linear range of $0-500 \mu \mathrm{g}$ ascorbic acid per $\mathrm{ml}$. The ascorbic acid content was expressed as $\mathrm{mg} / 100 \mathrm{~g}$ (fw) of sample.

\section{Sensory evaluation}

In-pack water accumulation and anaerobic head space generally results in odour development. In the present investigation, sensory analysis was carried out to evaluate odour and water accumulation. The sensory assessment for stored broccoli was carried out by a three member trained panel. The aroma was evaluated by modifying the procedure of Carvalho and Clemente (2004) and the water accumulation was evaluated as per the nine point scale proposed by (Rai et al., 1999). The complete score chart is presented in table 1.

During scoring, the intermediate scores were also given to the samples depending upon the perceived condition of the samples.

\section{Statistical analysis}

One-way analysis of variance (ANOVA) and multiple comparisons (Fisher's least significant-difference test) were used to evaluate the significant difference among different treatments at $p<0.05$ (Sun et al., 2007) using a statistical package (Statgraphics Plus, Statpoint Inc., USA). Data were expressed as means \pm standard deviation.

\section{Results and Discussion}

\section{Headspace concentration of $\mathrm{O}_{2}$ and $\mathrm{CO}_{2}$}

There was sharp change in the gaseous concentration of the packages during the first 24 hours and a near-steady was observed thereafter (Fig. 1). The gaseous concentration for $\mathrm{O}_{2}$ ranged between $3-8 \%$ and for $\mathrm{CO}_{2}$ it ranged between 6-9\% at the end of storage for all the perforated packages and for non perforated packages it ranged between $0-0.4$ $\%$ for $\mathrm{O}_{2}$ and $10-18 \%$ for $\mathrm{CO}_{2}$ in both the 
films. As clear from figure 1a that in LDPE film packages, the concentration of $\mathrm{O}_{2}$ arrived at $7.3 \%$ in perforated and $0.00 \%$ in nonperforated packages having head space (HS) 0.8 and it comes to $5.0 \%$ in perforated and $0.00 \%$ in non-perforated packages having HS 0.7 ; at the end of $1^{\text {st }}$ day of storage. The concentration of $\mathrm{O}_{2}$ in perforated LDPE packages remained above anaerobic levels till the end of storage period i.e. $6.0 \%$ in packages having $0.8 \mathrm{HS}$ and $3.9 \%$ in packages having $0.7 \mathrm{HS}$, but in nonperforated it became anaerobic after $1^{\text {st }}$ day and remained anaerobic till the end of storage. The concentration of $\mathrm{CO}_{2}$ in LDPE packages ranged between $6.0-8.1 \%$ in perforated and $15.9-10.0 \%$ in non perforated in $0.8 \mathrm{HS}$ packages; and in $0.7 \mathrm{HS}$ packages it ranged from 7.6-9.0\% in perforated and 18.1-10.4\% in non perforated. In LDPE perforated packages having $0.8 \mathrm{HS}$, enough amount of oxygen was available for aerobic respiration till the end of storage.

The concentration of $\mathrm{O}_{2}$ in $\mathrm{PP}$ packages arrived at $7.6 \%$ in perforated and $0.4 \%$ in non perforated packages having $0.8 \mathrm{HS}$; and it arrived at $5.1 \%$ in perforated and $0.3 \%$ in non perforated $0.7 \mathrm{HS}$ packages, at the end of storage period (Fig. 1b). The $\mathrm{CO}_{2}$ concentration recorded in PP packages was $5.9-7.2 \%$ in perforated and $15.2-10.1 \%$ in non perforated $0.8 \mathrm{HS}$ packages, and 7.6 $8.3 \%$ in perforated and $17.5-10.5 \%$ in non perforated packages having 0.7 HS. Concentration of $\mathrm{O}_{2}$ remained higher than concentration of $\mathrm{CO}_{2}$ in perforated $\mathrm{PP}$ packages having $0.8 \mathrm{HS}$ during the storage. The $\mathrm{CO}_{2}$ evolution rate of broccoli was recorded nearly 0.57 times the $\mathrm{O}_{2}$ consumption rate, which shows that small amount of water vapour might also be produced. The equilibrated values of in-pack concentration of $\mathrm{O}_{2}$ and $\mathrm{CO}_{2}$ for the different head spaces were observed to be significantly different, which shows that variability in the head space results in this type of behaviour.

\section{Weight loss}

The weight loss is a physiological event that can be limited by controlling storage temperature and humidity but also by using appropriate packaging. The weight loss (WL) was significantly higher in control samples than the samples packed in the films. The WL is less in PP films than LDPE films although the difference in the mean values was not significant. A glance at figure $2 \mathrm{a}$ and $2 \mathrm{~b}$ show that WL at the end of storage was negligible in samples sealed in polymeric films as compared to control samples that lost $8.34 \%$ of their initial weight. Even the change in head space did not produce any significant effect on WL of different samples kept in different films. The results obtained are quite comparable with the previous studies that packaging in polymeric films checked weight loss in perishable produce.

\section{Effect of MAP on pigments}

The present study reveals that, MAP resulted in a substantial maintenance of chlorophyll content of broccoli heads as compared to control samples. The retention of chlorophyll is more in LDPE as compared to PP films. In perforated and non-perforated samples in both type of package film significant difference in chlorophyll retention was recorded (Fig. 3a and $3 b$ ). In non perforated samples increase in chlorophyll was observed samples, which may be attributed to the high concentration of $\mathrm{CO}_{2}$ in these packages, but non-perforated packages become anaerobic and sample become non fit for human consumption after 24 hrs, (discussed in subsequent heading Sensory Evaluation). As shown in figure 3, an initial decrease in the chlorophyll was observed under all the packaging treatments, when the in-pack $\mathrm{O}_{2}$ was being consumed and a gradual increase in the $\mathrm{CO}_{2}$ levels was taking place. Under these conditions, the decrease in chlorophyll content was largely influenced by higher levels of in-pack $\mathrm{O}_{2}$ 
alone. These results were in agreement with the earlier reported observations of Moretti et al., (2003) where an initial decrease in the chlorophyll content was observed for green collards under the influence of high or ambient levels of $\mathrm{O}_{2}$. As the storage period progressed and a steady state was attained, $\mathrm{CO}_{2}$ build-up took place inside the film packages leading to stabilization in the chlorophyll retention levels in both types of film packages. This is in agreement with the earlier reported observations of Kader (1986) that storage of fruits and vegetables at high $\mathrm{CO}_{2}$ concentration may result in membrane protection due to direct action of $\mathrm{CO}_{2}$ on the membrane or by slowing senescence.

In LDPE film packages retention in chlorophyll was recorded in all the treatments at the end of storage. Among the perforated LDPE packages having 0.8 and 0.7 HS nonsignificant difference was observed, though maximum chlorophyll retention $(67.44 \%)$ was recorded in $0.7 \mathrm{HS}$ packages (Fig. 3a) this may be due to low in-pack $\mathrm{O}_{2}$ and high $\mathrm{CO}_{2}$ values recorded in these packages, which is in accordance with the earlier reported work of various researchers on broccoli, asparagus and some other vegetables (Barth et al 1993; Zhuang et al., 1994; Hirata et al., 1995; Saito and Rai, 2005). In the perforated PP film packages, chlorophyll retention was highest in 0.8 HS packages (Fig. 3b) at the end of storage, but no significant difference was observed with 0.7 HS packages. The decrease in chlorophyll was less in LDPE packages as compared to those kept in PP packages this may be due to higher retention of antioxidants, particularly ascorbic acid and $\beta$ carotene, in LDPE packages as compared to PP packages. The antioxidants generally present in vegetables are ascorbic acid and $\beta$ carotene, which protect chlorophyll by inhibiting with the reactions that degrade it (Schwartz and von Elbe, 1983). The control samples turned yellowish orange under the normal atmospheric levels of $21 \% \mathrm{O}_{2}$ and $0.03 \% \mathrm{CO}_{2}$, at the end of storage, which indicated that even low temperature storage could not avoid senescence in the broccoli florets which led to loss of chlorophyll. Under the MAP condition the $\beta$-carotene remains largely unaffected. A decrease in $\beta$-carotene content was observed during first 24 hours of storage for broccoli florets kept in both LDPE and PP films, but it became more or less stable when gaseous concentration in packages arrived at steady state (Fig. 4a and 4b). At the end of storage, no significant change in the $\beta$-carotene content was observed for the broccoli packed in LDPE. However, in PP films, $\beta$-carotene of the broccoli florets was more in packages having $0.8 \mathrm{HS}$ as compared to $0.7 \mathrm{HS}$ packages and non perforated samples. This result was in conformation with the earlier reported findings (Weichmann, 1986; Saito and Rai, $2005)$, that $\beta$-carotene remains largely unaffected and is generally retained under MAP conditions of low $\mathrm{O}_{2}$ and high $\mathrm{CO}_{2}$. The control samples showed higher values of $\beta$ carotene content.

\section{Changes in ascorbic acid content}

A decrease in ascorbic acid content was recorded in all the packaging treatment for both the films at the end of storage. The retention of ascorbic acid content was higher in LDPE packages as compared to PP packages. The ascorbic acid content decreased sharply (Fig. 5a and 5b) in all the packaged samples and in control till $1^{\text {st }}$ day of storage. In LDPE packages during the steady state, ascorbic acid increased slightly on the $3^{\text {rd }}$ day; and then declined to $9.740 \mathrm{mg} / 100 \mathrm{~g}$ fw in perforated packages having $0.8 \mathrm{HS}$ and $9.169 \mathrm{mg} / 100 \mathrm{~g}$ fw for packages having 0.7 HS; followed by 9.402 and 9.102 for non perforated LDPE packages having $0.8 \mathrm{HS}$ packages and $0.7 \mathrm{HS}$ respectively at the end of storage. In PP packaged samples final 
ascorbic acid content was recorded highest in non perforated packages having $0.8 \mathrm{HS}$ i.e. $7.853 \mathrm{mg} / 100 \mathrm{~g}$ fw followed by $7.267 \mathrm{mg} /$ $100 \mathrm{~g}$ fw for perforated packages having 0.8 HS samples at the end of storage period. In control samples ascorbic acid content of 5.17 $\mathrm{mg} / 100 \mathrm{~g}$ fw was recorded at the end of storage. The final level of ascorbic acid content was substantially higher for LDPE packaged samples than for PP packaged samples, indicating that different gaseous atmospheres had significant effect on ascorbic acid of broccoli packaged in LDPE and PP films.

\section{Sensory quality}

The shelf-life of the stored produce is influenced largely by the sensory quality parameters such as odour and water accumulations which suggest its suitability for human consumption; irrespective of objectively or instrumentally determined parameters. The results of the study suggest that perforated samples in both the films having $0.8 \mathrm{HS}$ remained sufficiently fresh till the end of storage in comparison $0.7 \mathrm{HS}$ which showed deterioration in odour after $1^{\text {st }}$ day of storage which changed to unacceptable odour at the end of storage period. The non perforated packages become anaerobic and unfit for consumption after 24 hours of storage. No off-odour was observed in perforated $0.8 \mathrm{HS}$ packages till $1^{\text {st }}$ day in LDPE, till $3^{\text {rd }}$ day in PP; and till $1^{\text {st }}$ day in 0.7 HS perforated PP packages (Fig. 6a and 6b). For the sample stored in perforated PP film very light off-odour was observed in packages having $0.8 \mathrm{HS}$ on $6^{\text {th }}$ day and for $0.7 \mathrm{HS}$ packages on $3^{\text {rd }}$ day of storage. For LDPE perforated samples, traces of off-odour were observed at the end of $3^{\text {rd }}$ day of storage in 0.8 HS packages; whereas for $0.7 \mathrm{HS}$ packages it was by the end of $1^{\text {st }}$ day. The odour in the 0.8 HS packages in both films changed to light off odour at the end of storage while in $0.7 \mathrm{HS}$ packages it changed to nearly strong off odour at the end of storage. Traces of off-odour were observed in control after $1^{\text {st }}$ day of storage which changed to very strong off odour at the end of storage period. The water accumulation was recorded less in LDPE films than PP films. It was also observed water accumulation was less in non perforated packages than in perforated packages. The water accumulation recorded was less for 0.8 HS packages as compared to $0.7 \mathrm{HS}$ packages In LDPE packages having 0.7 HS slight water accumulation was observed for non perforated packages, but moderate water accumulation was observed in perforated packages at the end of $3^{\text {rd }}$ of storage (Table 2 ).

Table.1 Score chart for sensory evaluation

\begin{tabular}{|l|l|l|}
\hline Designated score & Aroma / Odour & Water Accumulation \\
\hline 0 & -- & Heads completely wet and water accumulation \\
\hline 1 & Strong off odour & Heads and film moderately wet \\
\hline 2 & Medium off-odour & -- \\
\hline 3 & Light off- odour & Heads moderately wet \\
\hline 4 & Very light off-odour & -- \\
\hline 5 & No off-odour & Heads and film slightly wet \\
\hline 6 & -- & -- \\
\hline 7 & -- & Heads slightly wet \\
\hline 8 & -- & -- \\
\hline 9 & -- & No water accumulation \\
\hline
\end{tabular}

During scoring, the intermediate scores were also given to the samples depending upon the perceived condition of the samples. 
Table.2 Changes in various quality components of broccoli florets under different treatments

\begin{tabular}{|c|c|c|c|c|}
\hline Component & Packaging Film & Treatment & Initial Value & Final Value \\
\hline \multirow{10}{*}{$\begin{array}{c}\text { Total } \\
\text { Chlorophyll } \\
\text { (mg/100g } \\
\text { fw) }\end{array}$} & \multirow{5}{*}{ LDPE } & Perforated $0.8 \mathrm{HS}$ & \multirow{5}{*}{131.58} & 82.16 \\
\hline & & Perforated 0.7 HS & & 88.73 \\
\hline & & Non perforated $0.8 \mathrm{HS}$ & & 142.40 \\
\hline & & Non perforated $0.7 \mathrm{HS}$ & & 146.77 \\
\hline & & Control & & 39.08 \\
\hline & \multirow{5}{*}{ PP } & Perforated $0.8 \mathrm{HS}$ & \multirow{5}{*}{131.58} & 70.74 \\
\hline & & Perforated $0.7 \mathrm{HS}$ & & 79.26 \\
\hline & & Non perforated $0.8 \mathrm{HS}$ & & 140.53 \\
\hline & & Non perforated $0.7 \mathrm{HS}$ & & 143.98 \\
\hline & & Control & & 34.52 \\
\hline \multirow{13}{*}{$\begin{array}{c}\beta \text {-carotene } \\
(\mathrm{mg} / 100 \mathrm{~g} \\
\mathrm{fw})\end{array}$} & \multirow{5}{*}{ LDPE } & Perforated $0.8 \mathrm{HS}$ & \multirow{5}{*}{31.23} & 26.59 \\
\hline & & Perforated $0.7 \mathrm{HS}$ & & 25.97 \\
\hline & & Non perforated $0.8 \mathrm{HS}$ & & 25.02 \\
\hline & & Non perforated $0.7 \mathrm{HS}$ & & 25.19 \\
\hline & & Control & & 27.05 \\
\hline & \multirow{8}{*}{ PP } & Perforated $0.8 \mathrm{HS}$ & \multirow{8}{*}{31.23} & 26.36 \\
\hline & & Perforated $0.7 \mathrm{HS}$ & & 25.72 \\
\hline & & Non perforated $0.8 \mathrm{HS}$ & & 24.61 \\
\hline & & Non perforated $0.7 \mathrm{HS}$ & & 24.11 \\
\hline & & Control & & 27.09 \\
\hline & & Non perforated $0.8 \mathrm{HS}$ & & 140.98 \\
\hline & & Non perforated $0.7 \mathrm{HS}$ & & 149.74 \\
\hline & & Control & & 191.85 \\
\hline \multirow{10}{*}{$\begin{array}{l}\text { Ascorbic } \\
\text { acid content } \\
\text { (mg/100g } \\
\text { fw) }\end{array}$} & \multirow{5}{*}{ LDPE } & Perforated 0.8HS & \multirow{5}{*}{51.48} & 9.74 \\
\hline & & Perforated $0.7 \mathrm{HS}$ & & 9.17 \\
\hline & & Non perforated $0.8 \mathrm{HS}$ & & 9.4 \\
\hline & & Non perforated $0.7 \mathrm{HS}$ & & 9.00 \\
\hline & & Control & & 6.21 \\
\hline & \multirow{5}{*}{ PP } & Perforated $0.8 \mathrm{HS}$ & \multirow{5}{*}{51.48} & 7.27 \\
\hline & & Perforated $0.7 \mathrm{HS}$ & & 6.64 \\
\hline & & Non perforated $0.8 \mathrm{HS}$ & & 7.85 \\
\hline & & Non perforated $0.7 \mathrm{HS}$ & & 7.12 \\
\hline & & Control & & 5.17 \\
\hline
\end{tabular}


Fig.1 Gaseous concentration $\left(\mathrm{O}_{2}\right.$ and $\left.\mathrm{CO}_{2}\right)$ of broccoli florets at different levels of package head space stored under modified atmosphere. The plotted values are means of three replications per treatment along with their standard deviations


Fig.2 Weight loss (\%) of broccoli florets at different levels of package head space stored under modified atmosphere. The plotted values are means of three replications per treatment along with their standard deviations

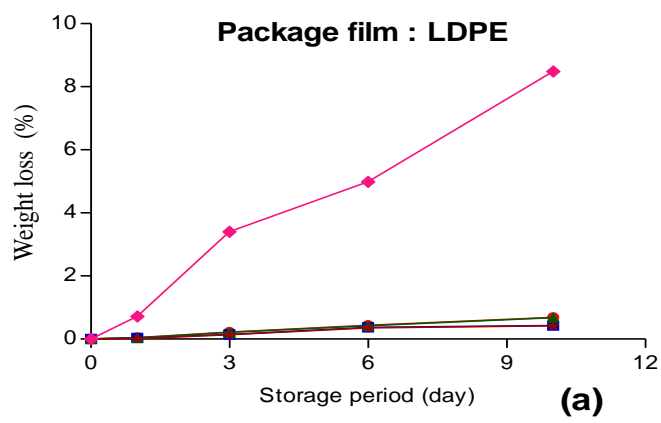

$\rightarrow \quad$ Perforated, HS: 0.8

$\rightarrow$ Non perforated, HS: 0.8

$\neg \quad$ Perforated, HS: 0.7

$\star \quad$ Non perforated, HS: 0.7

$\rightarrow$ Control

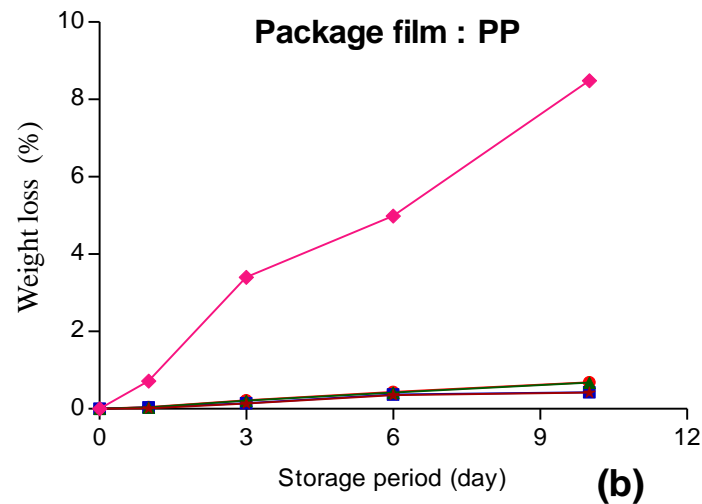

$\longrightarrow$ Perforated, HS: 0.8

$\rightarrow$ Non perforated, HS: 0.8

— Perforated, HS: 0.7

- Non perforated, HS: 0.7

$\neg$ Control 
Fig.3 Chlorophyll content of broccoli florets at different levels of package headspace stored under modified atmosphere. The plotted values are means of three replications per treatment along with their standard deviations


Fig.4 $\beta$-carotene content of broccoli florets at different levels of package headspace stored under modified atmosphere. The plotted values are means of three replications per treatment along with their standard deviations
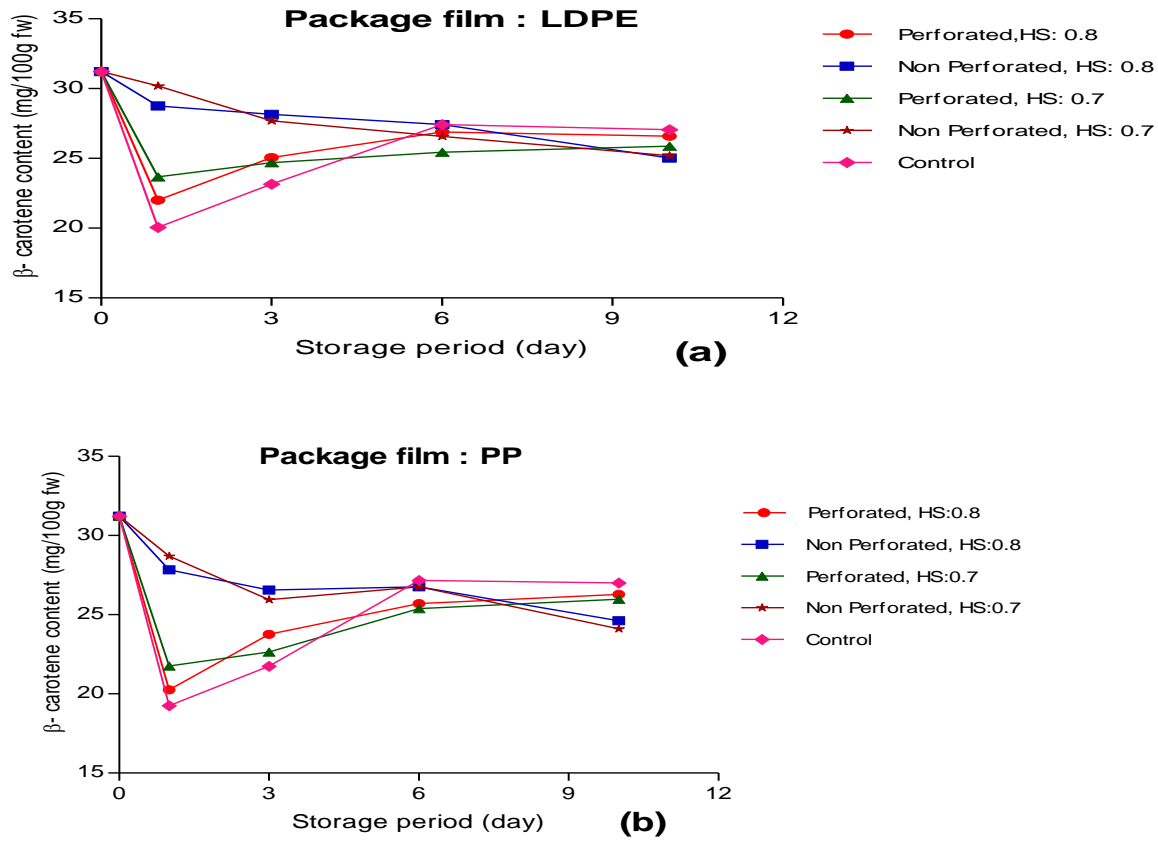
Fig.5 Ascorbic acid content of broccoli florets at different levels of package head space stored under modified atmosphere The plotted values are means of three replications per treatment along with their standard deviations
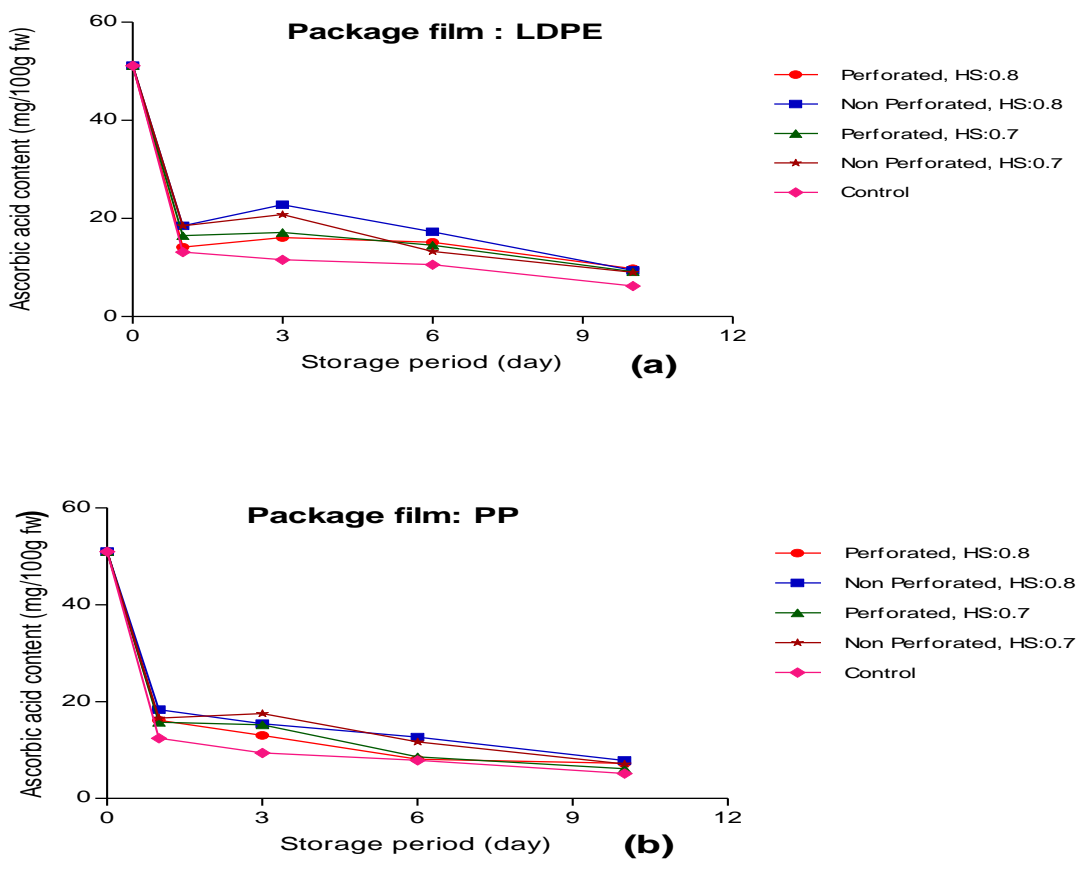

Fig.6 Odour rating of broccoli florets at different levels of package head space stored under modified atmosphere
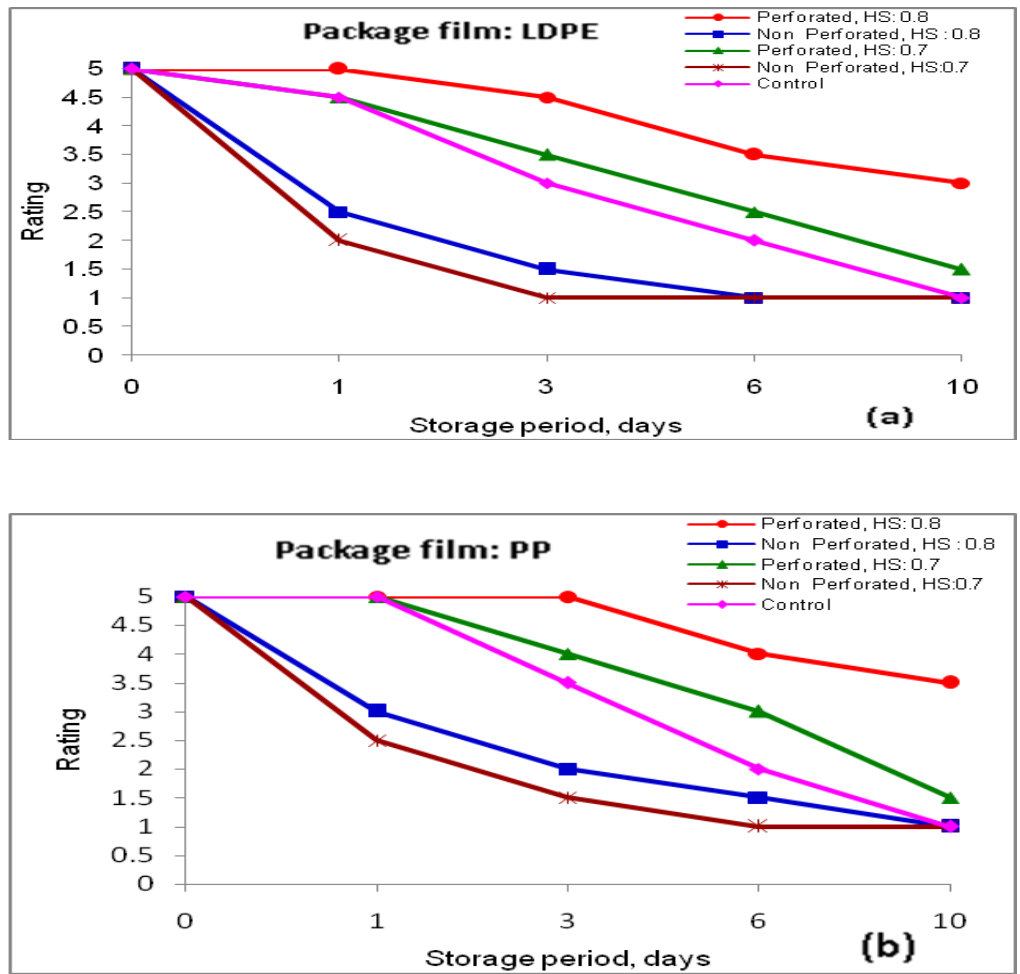
Fig.7 Water accumulation rating of broccoli florets at different levels of package head space stored under modified atmosphere
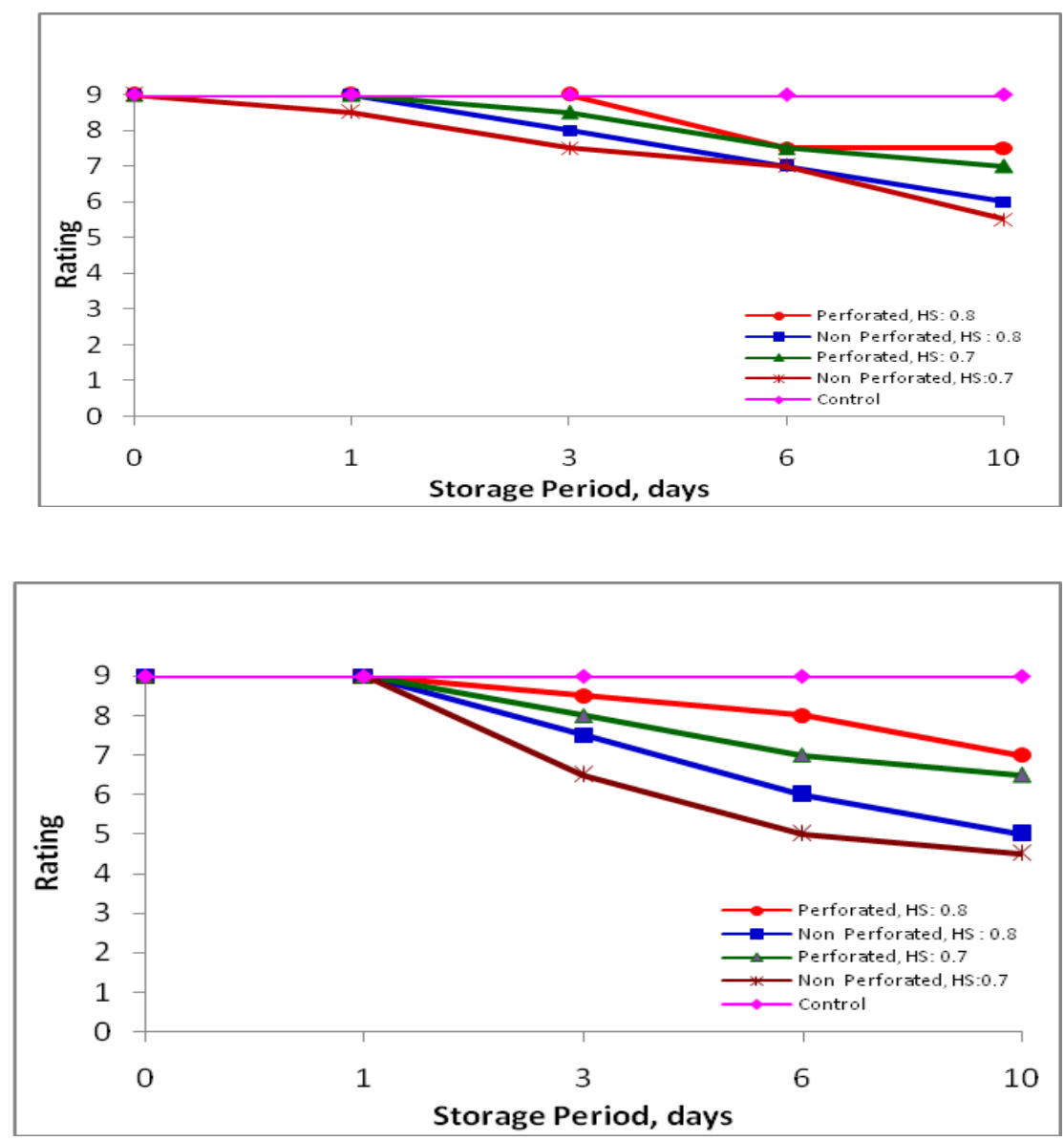

At the end of $6^{\text {th }}$ day visible water accumulation was observed in perforated and non perforated $0.7 \mathrm{HS}$ LDPE package. In LDPE having $0.8 \mathrm{HS}$ traces of water accumulation were observed in perforated packages at the end of $3^{\text {rd }}$ day and slight water accumulation in non perforated packages at the end of $6^{\text {th }}$ day (Fig. 7a). In PP packages, no water accumulation was observed in all the samples till $1^{\text {st }}$ day of storage. At the end of $3^{\text {rd }}$ day slight water accumulation in non perforated and perforated packages having 0.8 HS was recorded; and visible water accumulation in non perforated and perforated 0.7 HS packages was observed (Fig. 7b). This shows that decrease in head space increases the production of water vapour and the number of perforation and water vapour permeability of film are not enough to diffuse out the water vapour produced inside the packages. This results in water vapour condensation within the packages and in turn deterioration in sensory quality. Whereas in control samples no water accumulation was observed, but gives an unacceptable odour; florets get dried and turned yellowish brown making the control sample unfit for human consumption.

In conclusion, the broccoli heads were stored for 10 days at $15^{\circ} \mathrm{C}$ and relative humidity (RH) of $75 \%$ under different modified atmospheres created by using different packaging films (LDPE and PP) perforated (2 holes, $0.3 \mathrm{~mm}$ diametre each) and non perforated, having bag area of $0.14 \mathrm{~m}^{2}$ and 
thickness of 150 gauge; and by packaging different weight of broccoli resulting in the head space (HS) of 0.8 and 0.7 in polymeric film packages. The stored produce quality was adjudged on the amount of retention of chlorophyll at the end of storage period. The results of the study showed that broccoli packed in LDPE give higher chlorophyll retention in comparison to packed in PP may be due to lower in-pack $\mathrm{O}_{2}$ concentration.

Increase in chlorophyll content was recorded for non perforated packages in comparison decrease perforated packages. The non perforated packages became anaerobic after one day of storage and hence they are not fit for packaging of broccoli. The chlorophyll retention was higher in packages having 0.7 HS in comparison to the packages having 0.8 HS for both the films. The maximum retention of chlorophyll was recorded in perforated LDPE packages having $0.7 \mathrm{HS}$, but sensory evaluation showed that the sample showed intense off odour in comparison to slightly less retention of chlorophyll in perforated LDPE packages having $0.8 \mathrm{HS}$ with acceptable sensory quality. The $\beta$ carotene retention was observed higher in perforated LDPE packages having $0.8 \mathrm{HS}$ as compared to perforated PP packages having $0.8 \mathrm{HS}$. The retention ascorbic acid was also higher in the perforated LDPE packages having $0.8 \mathrm{HS}$ than the perforated PP package having $0.8 \mathrm{HS}$. It may be concluded that increase in $\mathrm{CO}_{2}$ concentration (7-9\%) along with decrease in in-pack $\mathrm{O}_{2}$ concentration (3$6 \%$ ) might have enhanced the retention of antioxidant components i.e. $\beta$-carotene and ascorbic acid for longer period, which in turn have resulted in increase in chlorophyll retention. The sensory evaluation and experimental data recorded shows that perforated LDPE package (2 perforation) of thickness 150 gauge and surface area $0.14 \mathrm{~m}^{2}$ having 0.8 head space generates a gaseous condition that could be beneficial for retention of various quality components of broccoli heads stored for 10 days at $15^{\circ} \mathrm{C}$ and $75 \%$ relative humidity.

\section{References}

Barth, M.M., Kerbel, E.L., Perry, A.K. and Schmidt, S.J. 1993. Modified atmosphere packaging affects ascorbic acid, enzyme activity and market quality of broccoli. $J$. Food Sci., 58: 140-413.

Brecht, J.K. 1995. Physiology of lightly processed fruits and vegetables. J. Hort. Sci., 30(1): 1821.

Carvalho, P.T. and Clemente, E. 2004. The influence of broccoli (Brassica oleracea var. italica) fill weight on post-harvest quality. Ciênc. Tecnol. Aliment. Campinas. 24(4): 646-651.

Dhaliwal, M.S. 2007. Handbook of vegetable crops, pp.183-186, Kalyani publisher, New Delhi.

Hansen, M.E., Sorensen, H.E. and Cantwell, M. 2001. Changes in acetaldehyde, ethanol and aminoacid concentration in broccoli florets during air and controlled atmosphere storage. Postharvest Bio. Technol., 22: 227-237.

Hirata, T., Nakatani, A., Ishikawa, Y., Yamada, C. and Katsura, S. 1995. Changes in chlorophylls, carotenoids, ascorbic acid and glutathiones of broccoli during storage in modified atmosphere packaging. J. Jap. Soc. Food Sci. Technol., 42: 996-1002.

Kader, A.A. 1986. Biochemical and physiological basis for effects of controlled and modified atmospheres on fruits and vegetables. Food Technol., 40: 99-104.

Klein, B.P. and Perry, A.K. 1982. Ascorbic acid and vitamin A activity in selected vegetables from different geographical areas of the United States. J. Food Sci., 47: 941945.

McDonald, S., Prenzler, P.D., Autolovich, M. and Robards, K. 2001. Phenolic content and antioxidant activity of olive extracts. Food Chem., 73: 73-84.

Moretti, C.L., Arajulo, A.L. and Mattos, L.M. 2003. Evaluation of different oxygen, carbon dioxide and nitrogen combinations employed to extend the shelf life of fresh-cut 
collard greens. Hort. Brass, 21: 676-680.

Nagata, M. and Yamashita, I. 1992. Simple method for simultaneous determination of chlorophyll and carotenoids in tomato fruit. J. Jap. Soc. Food Sci. Technol., 39: 925-928.

Nestle, M. 1998. Broccoli sprouts in cancer prevention. Nutr. Rev., 56: 127-130.

Pentima, J.H.D., Rios, J.J. and Clemente, A. and Olias, J.M. 1995. Biogenesis of off-odour in broccoli storage under low-oxygen atmosphere. J. Agric. Food Chem., 43: 13101313.

Rai, D.R. and Paul, S. 2007. Packaging requirements of highly respiring produce under modified atmosphere packaging: A review. J. Food Sci. Technol., 44: 10-15.

Rai, D.R., Saito, M., Masuda, R. and Y Ishikawa. 1999. Effect of MA packaging on glutathione content and quality of hiratake mushroom. Proc Spring Con. Jap. Soc. Hort. Sci., 347.

Rai, D.R., Tyagi, S.K., Jha, S.N. and Mohan, S. 2008. Qualitative changes in the broccoli (Brassica oleracea italica) under modified atmosphere packaging in perforated polymeric film. J. Food Sci. Technol., 45: 247-250.

Saito, M. and Rai, D.R. 2005. Qualitative changes in radish (Raphanus spp.) sprouts under modified atmosphere packaging in micro-perforated films. J. Food Sci. Technol., 42: 70-72.

Saito, M., Rai, D.R. and Masuda, R. 2000. Effect of modified atmosphere packaging on glutathione and ascorbic acid content of asparagus spears. J. Food Process. Pres. 24, 243-251.

Schreiner M., B.W., Peters, P. and Krumbein, A.
2007. Changes of glucosinolates in mixed fresh-cut broccoli and cauliflower florets in modified atmosphere packaging. J. Food Sci., 72: 585-589.

Schwartz, S.J. and Von Elbe, J. 1983. Kinetics of chlorophyll degradation to pyropheophytin in vegetables. J. Food Sci., 48: 1303-1306.

Sun, T., Powers, J.R. and Tang, J. 2007. Effect of enzymatic macerate treatment on rutin content, antioxidant activity, yield and physical properties of asparagus juice. $J$. Food Sci., 72: 267-271.

Techavises, N. and Hikida, Y. 2008. Development of a mathematical model for simulating gas and water vapour exchanges in modified atmosphere packaging with macroscopic perforations. J. Food Engg., 85: 94-104.

Vamos, V. 1981. Polyphenol oxidase and peroxidase in fruits and vegetables. Crit. Rev. Food Sci. Nutr., 49: 127-167.

Weichmann, J. 1986. The effect of controlled atmosphere storage on the sensory and nutritional quality of fruits and vegetables. Hort. Rev., 8: 101-127.

Wiley, R.C. 1994. Preservation methods for minimally processed refrigerated fruits and vegetables,. In Minimally processed refrigerated fruits and vegetables (Wiley, R.C., ed.) pp 66-134, Chapman and Hall, Inc., New York.

Zhuang, H., Barth, M.M. and Hildebrand, D.F. 1994. Packaging influenced total chlorophyll, soluble protein, fatty acid composition and lipoxygenase activity in broccoli florets. J. Food Sci., 59: 1171-1174.

\section{How to cite this article:}

Rakesh Kumar and Gurdarshan Singh. 2017. Changes in Quality of Broccoli Stored under Modified Atmosphere Packaging in Polymeric Films. Int.J.Curr.Microbiol.App.Sci. 6(7): 924937. doi: https://doi.org/10.20546/ijcmas.2017.607.114 